\title{
FORMA DAT ESSE: UNA ONTOLOGÍA CRISTIANA DEL ESPÍRITU HUMANO
}

\author{
JOAN MARTÍNEZ PORCELL \\ Univ. Ramón Llull
}

\begin{abstract}
RESUMEN: Forma dat esse fue un principio existencial de gran fecundidad antropológica. La filosofía cristiana aunque heredara explicaciones hilemórficas con las que se explicaba la naturaleza humana supo inscribir el ser y el actuar de la persona en el interior de la ontología de los espíritus creados. La corporeidad humana era presencia de un espíritu que existía en el confín y el horizonte de la eternidad. La plasticidad de las tendencias humanas era signo de su inteligencia y ésta debía definirse por su espiritualidad. La palabra era la comunicación del ser y el amor era el acto más importante de su fecundidad vital. No es de extrañar que la autoconciencia existencial se nos ofreciera como memoria de sí mismo y presencia del alma desde la patentización de su ser espiritual.
\end{abstract}

PALABRAS CLAVE: antropología, filosofía cristiana, persona, espiritualidad.

\section{Forma dat esse: a Christian ontology of human spirit}

ABSTRACT: Forma dat esse was initially high fertility existential anthropology. Christian philosophy inherited although explanations hylemorphic with explaining human nature knew register the being and doing of the person inside the ontology of created spirits. The presence of human corporeality was a spirit that existed in the boundary and the horizon of eternity. The plasticity of human tendencies was a sign of his intelligence and it should be defined by their spirituality. The word was being-communication and love was the most important act of his life fertility. No wonder that we offer existential self as memory itself and the presence of the soul from the patenting of his spiritual being. KEY WORDS: anthropology, Christian philosophy, person, spirituality

\section{LA METAFÍsICA CRISTIANA DE LA PERSONA: FORMA DAT ESSE}

Con este lema tan corto: forma dat esse, se entendía en la Escolástica la especial superación del orden sustancial griego que significó la metafísica del acto de ser. Efectivamente, la filosofía cristiana, aunque heredara explicaciones hilemórficas, supo inscribir el ser y el actuar de la persona en el interior de la ontología de los espíritus creados. Esta ontología del espíritu iluminaba de modo fecundo la unidad de la persona humana concibiendo el lema Forma dat esse como un principio antropológico fundamental de una gran riqueza.

En el marco de las diversas opiniones respecto del constitutivo formal de la persona, santo Tomás prefiere la definición de persona de Ricardo de San Víctor, quien definía la persona como subsistens distinctum incomunicabile, a la muy conocida de Boecio, como substancia individua rationalis naturae.

Santo Tomás prefiere la definición de persona de Ricardo de San Víctor porque sitúa la persona dentro de la ontología del espíritu. Tal definición de persona subraya que el ser está más allá del entendimiento de su naturaleza específica, es decir, que el ser no puede entrar en la definición de nuestra 
naturaleza de un modo esencial, ya que esto conllevaría negar nuestra condición creada. La persona tiene nombre propio, puesto que incluye fundamentalmente el subsistir en sí misma. Persona no es nombre universal ni abstracto sino que apunta directamente al ser subsistente, buscado en sí mismo.

Como consecuencia de ello, santo Tomás de Aquino sitúa los actos de conocimiento y amor personales en la consideración de la persona como realidad fundamentada en el ser. Toda persona se siente un ser cerrado en sí mismo, inmanente e incomunicable, portador de su propio ser, solo en sus propias decisiones; un ser que asume su propia existencia como una excepción original a la nada. Por otro lado, nuestra inteligencia nos reclama la posesión del ser, de cualquier ser, nuestro ser íntimo, el exterior a nosotros mismos, incluso el de Dios. Nuestra voluntad nos hace señores de nuestra propia actividad y nos ofrece un mundo enorme de posibilidades en las cuales nuestro ser se da a los otros. Pero nuevamente cuanto más se abre la persona y sale de sí misma mayor se vuelve la conciencia de su incomunicabilidad. La persona debe ser considerada metafísicamente como un ente individual, concreto, completo y compuesto.

La metafísica cristiana desbordó el nivel sustancial aristotélico, ya que la sustancia es únicamente potencia receptiva de la perfección de ser. La tentación constante de la filosofía ha sido eliminar la existencia actual de la propia noción de ser y tratarla como si fuera un sustantivo. Pero la perfección del ser no es esencial y supera el orden formal. El ser no es una cualidad ni una perfección más, ni tan siquiera la primera en el orden esencial, sino que el ser es acto y el acto de todos los actos.

El misterio de soledad y de presencia que descubrimos en toda persona se ve iluminado cuando se replantea la metafísica del acto de ser en el orden de la subsistencia. Cada persona es única y concreta y supone la unión y composición de muchos elementos estructurales distintos bajo un mismo acto de ser. Puede parecer que afirmar la persona como subsistens distinctum implica la negación de la comunicación, pero, pese a las apariencias, ocurre todo lo contrario. Gracias al grado ontológico eminente en que la persona participa el ser son posibles la percepción de la propia existencia, el conocimiento y el amor como comunicación de vida personal. El ser no sólo no incomunica sino que hace posible la comunicación y la relación interpersonal.

Por haber situado la persona en el horizonte del ser la filosofía cristiana pudo aprovechar las intuiciones teológicas que afectaban al conocimiento y el ser de Dios y de los ángeles desarrollando una metafísica del espíritu que le permitió centrar las operaciones y las facultades intelectuales y volitivas del hombre de un modo que fue mucho más allá del tratamiento formalista griego.

Consecuente con esta ontología del espíritu, Santo Tomás usará la tradición aristotélica hilemórfica, sobre la constitución del hombre como unidad sustancial compuesta de alma y cuerpo, pero sitúa la creación del alma humana a continuación de la creación de los ángeles, que reciben el ser directamente de Dios y esto le permitirá acceder a interesantes y fecundas intuiciones de hondo calado antropológico. Aquí destacaremos alguna de ellas. 


\section{LA UNIDAD PERSONAL}

El grado de unidad con el que la persona presenta sus actos y facultades, su concreción y subsistencia propias en el ser no provienen de la materia accidental. Aquello que distingue radicalmente un ente de otro en su subsistencia propia es el ser y no la forma. Forma dat esse significa precisamente que la existencia llega a la sustancia a través de la forma.

En primer lugar, el suppositum personal reside en el acto de ser que une en una sola existencia los co-principios sustanciales. No hay inconveniente en aceptar la explicación hilemórfica por la cual el hombre se compone de alma y cuerpo. El Aquinate afirma que el alma es el principio vital, la forma del cuerpo y la esencia del cuerpo vivo, siguiendo en esto a Aristóteles ${ }^{1}$. E incluso no hay inconveniente en dar una cierta prioridad a la forma sobre la materia, como solía hacer Aristóteles debido a su concepción cualitativa de la naturaleza; y así, los grados en que se manifiesta la vida señalan el grado de independencia de la forma respecto de la materia, y, en consecuencia, la automoción, la unidad y la autorrealización son niveles de la vida según el grado de inmanencia hasta llegar a la intelección en la que se rompe el circuito automático de estímulo y respuesta.

Pero explicar la unidad personal únicamente desde la mera unión de estos principios sustanciales no es suficiente. El Aquinate pone la unidad del supuesto personal en el acto de ser de modo que quien actúa es siempre la sustancia completa; no es el ojo el que ve, sino el hombre, a través de él. No se niega la unidad de la naturaleza humana concreta, pero la unidad de persona dice más que la unidad de naturaleza. La actualidad del ser es distinta a la actualidad de la forma y va más allá de ella. Consigue que la unión de los elementos sustanciales se realice en un acto nuevo, el acto de ser del supuesto personal, que al no ser meramente formal sitúa la persona humana en un grado determinado del orden de los espíritus creados. Es distinto preguntar a una persona "¿qué eres?» que preguntarle "¿quién eres?». A la primera pregunta podemos responder «hombre» o "animal racional», se trata de la unidad de naturaleza humana; a la segunda, en cambio, sólo responderemos adecuadamente con la concreción de un nombre de persona.

En segundo lugar, que la existencia llega a la sustancia a través de la forma conlleva también que el espíritu humano es la última de las sustancias espirituales en el orden de la creación, precisamente después de los ángeles ${ }^{2}$. El alma humana no es un ángel sino que es un espíritu creado para vivir y conocer a través de la unión sustancial con un cuerpo. De ahí que no existan los estados psíquicamente puros. El hombre no es un animal de estímulos sino de realidades ${ }^{3}$;

\footnotetext{
1 Santo Tomás, De Anima, lect. 9 n. 341.

2 Lobato, A., El pensamiento de Santo Tomás de Aquino para el hombre de hoy, 3 vols. Edicep. Valencia(2003).

3 Santo Tomás, S.Th I, q. 78, a. 2; De Anima, lect 9 n. 341.
} 
y la dualidad de operaciones de la cual es capaz la persona no implica el dualismo de sustancias. Para la concepción de la antropología cristiana, el espíritu no es espíritu puro sino un alma que anima el cuerpo haciéndolo humano, y el cuerpo no es conglomerado sino un cuerpo anímico y animado 4 .

La existencia llega primero al alma y, a través de ella, al cuerpo que anima. Este orden en la recepción del ser es importante para comprender que la unión de la existencia con el alma es tal que puede subsistir más allá de las condiciones materiales en las que se encuentra durante esta vida. La afirmación de la inmortalidad del alma después de que la muerte la haya separado de su cuerpo sólo es posible por la unión intrínseca que existe entre la existencia y las formas simples aunque estén destinadas a animar un cuerpo. El compuesto puede descomponerse pero no la sustancia simple. Un círculo de madera o de hierro (compuesto) puede dejar de ser, puede quemarse o quebrarse, pero un círculo en sí mismo, como forma geométrica simple, no puede dejar de ser redondo. Del mismo modo que la existencia del círculo está esencialmente unida a ser siempre redondo, así pertenece la existencia al alma.

Aunque la metafísica cristiana del espíritu situaba el alma como espíritu creado y no únicamente como forma de un cuerpo vivo, el acto de ser del supuesto personal asumió la explicación hilemórfica sustancial. La unión de alma y cuerpo forma parte de la unidad personal, precisamente en cuanto unidad de naturaleza, aunque no dice la última palabra sobre la unidad de persona que reposa en el ser.

Esta unidad sustancial se manifiesta en tres niveles: el vital, el psíquico y el espiritual. En el nivel vital, el hombre se encuentra unido a la vida a través de su cuerpo, y, de esta manera, el hombre se nos manifiesta como una estructura sustantiva capaz de independencia del entorno. El nivel psíquico refleja la unidad individual del hombre irreducible a lo físico-químico; se trata de la zona de la emotividad. Y el nivel espiritual se manifiesta en los actos espirituales de naturaleza específica, como son la conciencia de sí, la capacidad de autopresencia, el conocimiento universal, la prefijación de fines, la comprensión de sentido, la previsión de futuro, la libertad y la responsabilidad. En todas estas acciones, la persona no se circunscribe al espacio o tiempo propios de la materia ${ }^{5}$.

\section{LA CORPOREIDAD HUMANA: PRESENCIA, ROSTRO Y CARNE.}

Debido a la unidad existencial única de la persona humana sucede que tal unidad sustancial humana explica a la vez tanto las funciones biológicas como las capacidades superiores. Lo más propio de la naturaleza humana consiste en darse los fines y escoger los medios; en esto consiste la libertad con la cual

4 SAnto Tomás, S.Th I, q. 76, a. 1; C.G II, c. 68.

5 Santo Tomás., C.G II, c. 68. 
el circuito biológico se rompe y permanece abierto. En el hombre no todo está programado, sino que sus objetivos necesitan elección y aprendizaje. Y esto podemos afirmarlo tanto de los objetivos racionales como de los más básicos. Decidimos nuestra profesión o nuestras creencias, pero también decidimos hablar o comer. En la persona humana el pensamiento es tan radical como la propia biología, ya que incluso satisfacer el instinto exige la intervención de la razón.

Las funciones de la corporeidad humana no nacen únicamente de su estructura biológica sino sobre todo del hecho de ser un elemento constitutivo de esta realidad unitaria y substantiva que es la persona humana. Por esta razón podemos distinguir entre cuerpo y organismo. El organismo es el soporte biológico de la persona, pero la corporeidad humana es mucho más. Como afirma G. Haeffner, "En el vaivén entre el tener el cuerpo (organismo) y el ser cuerpo (soma) está la corporeidad humana» ${ }^{6}$.

El cuerpo es a la vez presencia, rostro y carne ${ }^{7}$. El cuerpo es soma en cuanto modo de hacerse presente al mundo. El ser humano es un habitante del mundo y con su actividad modifica su entorno para poder sobrevivir. A diferencia de los animales, no se adapta al entorno sino que adapta el entorno a sus necesidades; por esto tala bosques, construye carreteras, instala luz y teléfono. La persona no pasa por el mundo sino que se queda en él; lo habita. Habitar significa estar en un lugar poseyéndolo, teniéndolo. El único habitante del mundo es la persona humana porque habitar un lugar implica modificar el entorno.

El cuerpo es también rostro, es decir, medio de relación íntersubjetiva, de modo que el reír, el llorar, o acariciar nos hacen interlocutores de un mundo humano. Finalmente, el cuerpo es también carne, es decir, poder de transformación del mundo y factor de limitación propia, ya que el cuerpo hace posible que el hombre tenga cosas. El trabajo humano o el progreso de la técnica como actividad de dominio y apropiación del entorno no es más que un prolongamiento de la función corporal por la cual la persona está en el mundo.

El ser llega al cuerpo a través del alma; el cuerpo está destinado a servir biológica y funcionalmente a la racionalidad y por esta razón no está especializado. Es un sistema en el que todos sus elementos están funcionalmente interrelacionados para realizar tareas que no son orgánicas. Toda su estructura, desde el bipedismo, la posición libre de las manos, la posición erecta o la posición frontal de los ojos hasta el peculiar proceso de desarrollo cerebral, implican una radical innovación en el proceso evolutivo.

Las manos humanas son un instrumento inespecífico, es decir, son instrumento de instrumentos y de lenguajes ${ }^{8}$. La mano humana no es tan resistente como una pezuña, ni tan fuerte como una garra, porque no está destinada

\footnotetext{
6 Haeffner, G., Antropología filosófica. Herder. Barcelona (1986) p. 107-126.

7 Laín Entralgo, P., Cuerpo y alma, estructura dinámica del cuerpo humano. Espasa Calpe. Madrid (1992) p. 243-273.

8 Aristóteles, De Anima, 432 en: Calvo Martínez, T., Aristóteles. Acerca del alma. RBA. Barcelona (2003).
} 
exclusivamente ni a correr ni a agarrarse a nada. No tiene una función biológica específica porque debe permanecer máximamente disponible a los muchos significados y lenguajes humanos; con ella podemos expresar amistad, ternura, agresividad o miedo. Lo mismo ocurre con la voz humana. La voz es más que un sonido, es sonido articulado que exige órganos especiales, que le permiten dotar al sonido de significación simbólica o convencional.

El cuerpo humano reviste un peculiar carácter personal, de modo que mientras el vestido es algo extrínseco para nosotros, el cuerpo nos es intrínseco. La persona es humana porque está encarnada y el cuerpo es humano en la medida en la que está animado por el espíritu. En definitiva, el hombre es cuerpo inteligente e inteligencia corporalizada.

\section{LA ESPIRITUALIDAD DE LAS FACULTADES HUMANAS COMO HÁBITOS}

El hombre es capaz de conocer de manera abstracta y universal, es decir, puede llegar a conocer la esencia de las cosas. Por la inteligencia puede descubrir propiedades constantes y esenciales en las cosas materiales, ya que el objeto propio y adecuado del entendimiento humano es la naturaleza o esencia de los seres materiales ${ }^{9}$. También puede conocer las realidades inmateriales, como su propio pensamiento o su propio ser, pero de modo indirecto ${ }^{10}$. Toda realidad, en tanto que existente, es objeto del entendimiento, ya que el objeto del intelecto humano es infinito ${ }^{11}$.

El entendimiento humano presenta una serie de características que muestran su espiritualidad: la infinitud, por la que el entendimiento permanece abierto a todos los seres, de modo que no existe un pensamiento último, sino que está potencialmente abierto al infinito; la alteridad, es decir, la capacidad de captar las cosas en un horizonte en el cual aparecen como objetos dentro de un mundo; la reflexión, que nos permite conocernos a nosotros mismos, etc.

Pero es la nota de la inmaterialidad la que mejor capta la espiritualidad de las facultades humanas, ya que aquello que define la materia es precisamente la no-simultaneidad entre el movimiento y su final. En cambio, en el pensamiento asistimos a un proceso en el cual el inicio es simultáneo con el final. Esta instantaneidad o simultaneidad es necesariamente inmaterial, es decir, que el pensamiento no es orgánico.

La inteligencia necesita el cerebro pero únicamente como causa instrumental, ya que es el hombre el que piensa con su cerebro y no éste el que piensa autónomamente. Pensamos cuando queremos pensar ${ }^{12}$. El materialismo puede superarse con sólo atender debidamente a las características mencionadas del

SAnto Tomás, $S$. Th I. q. 85 , a. 8.

10 Santo Tomás, $S$. Th I. q. 88 a. 1 y $2 ; S . T h$ I. q. 13 , a. 5.

11 Santo Tomás, $C . G$ II. c. 98.

12 Marina, J. A., Teoría de la inteligencia creadora, Anagrama. Barcelona (1998) p. 229. 
entender humano, como son la reflexión sobre el propio sujeto, la infinitud potencial y la universalidad de su objeto.

El entender, no ya como determinación cualitativa del hombre, sino en su misma naturaleza de conocimiento, ha de ser concebido como acto, y resolverse últimamente en el acto de todos los actos, que es el acto de ser. De algún modo, podemos afirmar que la persona entiende y se comunica porque participa del ser en grado eminente. Así es como damos fundamento ontológico al propio acto de intelección, en cuanto manifestación del ser. Y, al mismo tiempo, al reconocer la naturaleza auto-comunicativa de todo acto, abrimos trascendentalmente la persona a la comunicación por el conocimiento y el amor.

Pertenece a la esencia del conocimiento el decir o expresar lo entendido. No hay anterioridad del decir o locución mental respecto del entender; el verbo se funda en la naturaleza fecunda del entendimiento, y es como su esplendor. Pero tampoco el decir es posterior al entender. La aprehensión y la manifestación intelectual son dimensiones de la misma perfección, de modo que habrá que mantener la identidad del acto de entender y el acto de decir la palabra mental. Lo entendido se comporta como algo constituido por el entender. La palabra mental es lo principalmente entendido, porque en ella se entiende la cosa.

El desdoblamiento esencial al conocimiento no es el que cree el intuicionismo, entre sujeto inteligente y objeto entendido, sino el constituido por la actividad del pensamiento que entiende pensando, y expresa y forma en sí mismo, en cuanto inteligente en acto, lo entendido en acto. El conocimiento muestra siempre unidas la conciencia existencial de todo acto de entender y la aprehensión objetiva de los objetos entendidos. La fecundidad manifestativa e inmanente pertenece al entender en cuanto acto y en virtud de la naturaleza comunicativa de todo acto. Si entender es decir, por la misma naturaleza del acto, es porque la locución surge de la fecundidad vital del ente.

La actividad intelectual no es un acto distinto añadido al ser en acto del entendimiento, sino que pertenece al mismo acto en cuanto posesión de sí mismo. La auto-presencia consciente, constituida por la posesión inmaterial del ser por parte de la persona, y la emanación locutiva de la palabra mental no son dos estructuras de composición acto-potencial, ni significan un nuevo acto añadido al ser de la persona. El verbo mental no emana del entendimiento en cuanto que éste pasa de la potencia al acto, sino en tanto que, por ser actualmente inteligente, la palabra mental surge como el acto del acto.

En la simplicidad del acto de entender, y en virtud de su misma actualidad comunicativa, la manifestación sigue a la auto-presencia. Si sólo la intencionalidad expresada en acto segundo consuma la infinitud intencional de la persona, ello es debido a la limitación entitativa de la naturaleza creada, pero, en sí misma, la fase manifestativa es comunicación de la actualidad del ente, poseído en su ser por la autopresencia del acto en sí mismo. El acto surge del acto; el acto expresado dice el acto que ya es y que se posee por su ser y es expresado por la naturaleza comunicativa del acto.

La espiritualidad de la voluntad humana expresa una plasticidad semejante a la que hemos descubierto al tratar del entendimiento. También en ella se nos 
manifiesta la ontología de un espíritu encarnado en el mundo. La voluntad humana es la tendencia natural hacia un bien conocido por la inteligencia. En la experiencia diaria encontramos tendencias sensibles (deseos) y tendencias intelectuales (querer), y aunque a menudo nos cueste discernirlos sabemos que podemos querer una cosa sin desearla.

La voluntad es una facultad operativa de orden espiritual, lo cual se manifiesta de distintas formas. En primer lugar, la voluntad humana es capaz de reflexión, no en el sentido de conocer su acto, ya que la voluntad no es una facultad cognoscitiva, sino porque la voluntad quiere su propio querer. Incluso para no querer la voluntad necesita querer: quiere no querer. En segundo lugar, la voluntad no depende de las coordenadas espacio temporales. Amar, por ejemplo, se da en el espacio y en el tiempo pero no depende de ellos; de ahí que podamos querer más y mejor. Nada material tiene esas características. Y en tercer lugar, la voluntad puede moverse por valores abstractos como el honor o la justicia, por ejemplo. Es un hecho de experiencia común que nada creado satisface el deseo de felicidad; siempre queremos más. Estas tres razones sitúan la voluntad como facultad de un ser espiritual subsistente y no únicamente como forma viva de un cuerpo orgánico.

En la dinámica volitiva actúa primero la inclinación al bien en general, llamada voluntas ut natura; y luego la elección de los medios para conseguir la felicidad, llamada voluntas ut ratio. La primera no la podemos modificar, la segunda sí, de ahí que deseamos ser felices pero no lo escogemos, sólo escogemos cómo serlo. La voluntad humana manifiesta un ser que desborda los entes de este mundo, por esto queda indeterminada ante un bien finito.

\section{LA AUTOCONCIENCIA COMO CONOCIMIENTO EXISTENCIAL DEL PROPIO YO}

Es evidente que si tratamos de conocimiento esencial, no es lo mismo conocer una piedra que conocer de un modo reflejo el conocimiento por el que conocemos la piedra; y, ya que los actos se distinguen por los objetos, se tratará de dos actos distintos. Pero si tratamos de conocimiento existencial bastará un solo y mismo acto, si bien con dos dimensiones, una esencial y otra existencial.

Todo conocimiento versa sobre un objeto, pero arraiga en un sujeto, del cual procede, de modo que en todo acto de conocimiento no sólo conocemos el objeto, sino también indirectamente el propio sujeto cognoscente. En un acto de conocimiento conocemos directamente el objeto, pero también conocemos al sujeto aunque indirectamente y sin imagen intencional. El conocimiento del propio yo puede ser a modo de vivencia o conciencia concomitante, o a modo de reflexión. La conciencia concomitante es la dimensión existencial, vivencial y subjetiva de un acto de conocimiento; en cambio, la reflexión es otro acto nuevo de conocimiento que toma por objeto un conocimiento anterior, y es objetivo, esencial y explícito. Con esta conciencia existencial de uno mismo, 
conocemos que conocemos y conocemos que existimos, pero aún no sabemos nada de nuestro conocimiento o nuestro yo.

Por otro lado, habrá que distinguir también entre el conocimiento existencial en acto, es decir, cuando de hecho ejercemos este conocimiento; y el conocimiento existencial en hábito, es decir, cuando podemos conocer que existimos con sólo querer conocerlo. Toda persona posee esta conciencia existencial en hábito, es decir, al modo de un hábito objetivo de conocimiento, si bien el paralelismo es sólo analógico, pues mientras el hábito de conocimiento se constituye por las especies inteligibles, la conciencia existencial de uno mismo no es un hábito objetivo.

Lo importante es que tal hábito tiene en sí mismo todo lo necesario para pasar al acto de conocimiento, sin recibir nada nuevo. La persona no necesita ninguna nueva determinación específica para el conocimiento existencial de sí mismo, sino que basta la sola presencia del alma. Para conocer nuestra propia existencia nos basta con conocer algo; si necesitamos la especie es para conocer ese algo, pero no para conocer la existencia del propio yo. Los actos de conocimiento, en orden a esta percepción existencial, no son recibidos en el propio yo, como lo son las especies en el orden del conocimiento esencial, sino que proceden del mismo yo. La persona posee un conocimiento habitual de su existencia por sí misma.

Y aquí vuelve a emerger de un modo diáfano el principio fundamental de la ontología del espíritu humano, forma dat esse, ya que el conocimiento habitual se sitúa en la misma sustancia del alma. Existe un conocimiento esencial del propio yo, tanto por simple aprehensión - a partir del conocimiento que tenemos de las cosas sensibles_-, como por el juicio; pero, para nuestros fines, nos interesa ahora el conocimiento existencial del propio yo en hábito. El sujeto tiene en sí mismo lo necesario para este tipo de conocimiento; le basta la presencia del alma como noticia substancial de ella misma; este conocimiento procede del mismo yo, de tal modo que cabría preguntarnos si en la dicotomía sujeto-objeto, que necesariamente crea toda intencionalidad, hemos olvidado lo más importante del acto de conocer: que es acto, y acto emanado de la fecundidad con que el espíritu posee el acto de ser.

El alma humana, aunque sea la última de las substancias espirituales por poseer un ser propio, conserva la inteligibilidad, que es la característica esencial del espíritu. Aunque su intelectualidad actúe de un modo propio, a través de las cosas materiales, y por un proceso de paso de potencia al acto, la mente misma es inteligible en acto, si bien no por su intrínseca inteligibilidad, sino en cuanto es inteligible en hábito. Es cierto que para que el alma actualice esta disposición habitual le es necesaria la actuación de sus operaciones, pero, respecto del conocimiento de sí misma, este hábito es una disposición permanente, parecida a un hábito cognoscitivo, anterior a toda intelección.

La sola presencia del alma no provoca el conocimiento de su propia esencia, pero sí la percepción intelectual de su propia existencia. Esta experiencia existencial que toda persona tiene de sí misma está constituida por la subsistencia en sí de la mente, propia de una sustancia inmaterial, ya que la autoconciencia, 
la subsistencia de sí mismo y la inmaterialidad coinciden. Esta inteligibilidad habitual es la causa de la actividad de su entendimiento agente y de la capacidad receptiva de la mente respecto de los inteligibles abstraídos de las imágenes.

La aparición de la esencia inteligible se produce por esta reflexión connatural, que es la misma subsistencia del alma, o su propio ser. La presencia íntima del espíritu en su ser es anterior y originante de la intelección. Esta debe ser entendida como la patentización del ente desde la fecundidad del espíritu. Anterior a la inteligibilidad de las esencias, el acto de entender se constituye por su estructura de auto-presencia, en la que se ejercita la actualidad de una sustancia que posee el ser. Todo entender es, antes que especificado por una especie inteligible, ejercicio de la presencia del acto a sí mismo, auto posesión íntima del ser. El entendimiento entiende por la especie, así como algo es por la forma; pero el ser de tal forma es el mismo entender, en cuanto acto.

Santo Tomás llega a afirmar que, dada la unidad substancial humana, la pervivencia más allá de la vida del cuerpo no le corresponde al alma de un modo natural. No se puede entender la solución aportada por el Aquinate, sin una firme metafísica del ser y quedándose únicamente en el esquema hilemórfico. De ahí que insistiéramos en la especial iluminación que se produce en la antropología cristiana desde la metafísica de los espíritus como receptores del ser creado por Dios.

El alma continúa existiendo más allá de la muerte ${ }^{13}$, precisamente porque el alma es espiritual. Hay dos maneras de comunicar el ser a los entes: cuando el acto de ser se comunica al compuesto y, así, al desintegrarse su unión, desaparece el ser que les corresponde; y el acto de ser comunicado al alma y ésta comunicando el ser al compuesto. Forma dat esse significa precisamente que la existencia pertenece inmediatamente al alma; esto es, no a través de un intermediario, sino por sí misma. Lo que pertenece a algo por sí mismo, y como la propia perfección de su naturaleza, le pertenece necesariamente, siempre y como una propiedad inseparable.

\section{LA CUESTIÓN DEL SENTIDO}

La persona está en ser por encima del mundo natural; es una realidad original con carácter progresivo y auto creativo. La historicidad, sin duda, es un factor estructural del crecimiento de la persona, pero entender la historicidad humana en el sentido de mera fugacidad o inconsistencia de la vida sería aplicar al hombre el concepto de tiempo de las cosas. El tiempo físico es ciertamente mero fluir de instantes, pero el tiempo humano es articulación del pasado, el presente y el futuro en un único proyecto vital. Tampoco sería suficiente entender la historicidad como mero cambio o devenir ya que la historicidad humana

13 Santo Tomás, S. Th I. q. 89, a. 1. 
es crecimiento y desarrollo de capacidades; es el proceso voluntario y consciente de acercar el estado objetivo en el que nos encontramos al ideal perseguido.

Como vimos en su momento, la estructura corporal del ser humano nos lleva a realizarnos en un entorno espacio-temporal con unos elementos esenciales que implican la encarnación, la temporalidad y la inter-personalidad. Estos tres elementos hacen de la temporalidad humana un proceso ontológicamente diferente de la inestabilidad y el crecimiento de la pura historicidad. El hombre puede trascender el tiempo porque en él convive lo temporal con lo intemporal. En la persona el momento no es una unidad cronológica, sino vital, de modo que el engarce de unos momentos con los otros establece una continuidad articulada que es su trayectoria biográfica.

Toda pretensión humana es pretensión de felicidad. Para los griegos, la felicidad consistía en la vida buena que incluía, entre otras cosas: la familia y los hijos, una cantidad moderada de riqueza, unos buenos amigos, la suerte o fortuna que nos aleje de la desgracia, la fama, el honor, la buena salud, la contemplación de la verdad y la práctica de la virtud. El sentido de la vida es la percepción de la trayectoria, satisfactoria o no, de la propia vida.

Cuando se ha perdido el sentido de la vida empieza la penosa tarea de buscar un motivo para afrontar el vivir. Hoy día se da una grave crisis de los proyectos vitales ${ }^{14}$. La ausencia de motivación y de ilusión es el comienzo de la pérdida del sentido de la vida. Para recuperarlo necesitamos una tarea que nos ilusione y saber afrontar las grandes verdades y las respuestas a los interrogantes existenciales. Los modelos prácticos referidos al sentido de la vida que han llegado con la postmodernidad son fruto del nihilismo: el carpe diem de cada momento fugaz; el pragmatismo del interés; o el bienestar como consumismo de dinero o el afán de poder.

La historicidad propone al hombre la cuestión del sentido de su existencia. El tener que hacerse con los otros en el mundo es fuente de inquietud, debido al desfase entre lo que se tiene o se es y lo que se pretende ser o tener. La persona humana se ve obligada a palpar sus propios límites. El dolor exterior es causa de un mal presente contrario al cuerpo, en cambio el sufrimiento es desgarramiento íntimo con dolor interno. Por eso hay muchas clases de sufrimiento: tristeza, ansiedad, angustia, miedo, desesperación.

Lo mismo cabe afirmar de la muerte. Nadie tiene la experiencia de la muerte, pero es una experiencia central en la vida. Su significado está relacionado con la existencia hasta el punto de que el miedo a morir es el conocimiento instintivo de una amenaza incesante e imprevisible no encuadrada en nuestro horizonte vital. Por otro lado, no podemos rehuirla ya que «nos pone ante lo absolutamente imprevisible» y la percibimos como una ineludible posibilidad. Debemos, no obstante, diferenciar entre el morir y la muerte. El morir en cuanto muerte clínica es el camino hacia la muerte en sentido antropológico.

14 Rojas, E., La conquista de la voluntad, Temas de Hoy, Madrid (1994) 19-23. 
Se han dado otras explicaciones menos escolásticas para explicar cómo lo orgánico y lo psíquico son complementarios. El problema de la supervivencia no es una demostración filosófica estricta; tampoco quienes defienden las pruebas racionales de la inmortalidad lo hacen hoy así. Blondel o Maritain tratan esta cuestión en un marco existencial más amplio. La riqueza ontológica adquirida en el acontecer existencial es de una densidad que no se corresponde con la nada. Fieles a la alteridad y la historicidad, la plenitud del ser humano está en la plenitud de su libertad y en el desempeño del amor perdurable, por encima del espacio y el tiempo.

Viktor E. Frankl es el fundador de la logoterapia o tercera escuela vienesa de psicoterapia ${ }^{15}$. No nos ocuparemos de la psicoterapia en cuanto escuela científica de psicoanálisis, sino de la previa concepción antropológica que supone. El psicoanálisis mira el alma humana como un todo constituido de un modo atomístico y opera con conceptos de energética de impulsos y dinámica afectiva de modo que reduce lo psíquico a impulsividad. Ante esta concepción atomizante, energética y mecanicista que nos presenta el hombre como un automatismo de carácter anímico, el análisis existencial de Frankl mantiene la persona como una unidad y una totalidad corporal psíquica y espiritual.

En la metafísica cristiana, la persona establece una cierta posición en el ser, ya que se refiere directamente a la sustancia intelectual individual, cualquiera que sea y de cualquier modo que se individúe. Si lo subsistente es único, parece lógico preguntarnos cuál es la unidad de la persona. Aparte de la unidad como principio del número y de la matemática, que es sólo un accidente que añade al ser la medida, existe otro sentido de la unidad por el que es un trascendental convertible con el ente y no una disposición sobreañadida a la esencia de la cosa, y que añade al ser la indivisión. La subsistencia se debe al supuesto que es el todo que posee la naturaleza con el modo de ser por sí mismo. El ser perfecto sin ninguna dependencia, que llamamos subsistir, es el propio de la sustancia individual completa, que excluye cualquier comunicabilidad ya que es un todo independiente.

La existencia es el modo característico y singular de ser del hombre, ya que «ex-sistir» significa etimológicamente situarse («sisto») fuera de («ex»), ponerse frente a sí mismo, de manera que el hombre sale del nivel de lo corporal psíquico y distanciándose de sí mismo como organismo psicofísico se constituye en persona espiritual como tal. Para Frankl ninguna unidad psicosomática es suficiente para constituir su totalidad; a esta última pertenece esencialmente lo espiritual. Frankl es heredero del pensamiento dimensional de N. Hartmann y M. Scheler, quienes conciben lo fisiológico, psicológico y noológico como dimensiones del hombre unitario-total.

En esta tridimensionalidad del cuerpo, alma y espíritu, es ante todo la dimensión de lo espiritual la que constituye el ámbito de lo humano. Es cierto que no es la única región ontológica a la que pertenece el hombre, pues el

15 FrankL, V. E., Logoterapia y análisis existencial. Herder. Barcelona (1994) p. 68. 
hombre es una unidad y totalidad corporal-psíquico-espiritual, pero la espiritualidad del hombre es algo que distingue al hombre, que le corresponde sólo a él y ante todo a él. Frankl habla de la aproximación de la psicología a la "persona», la «existencia», o «lo espiritual», según que el modo de acercamiento sea fenomenológico, antropológico u ontológico.

En este sentido, el análisis existencial, además de una práctica clínica, se revela como análisis referido al ser responsable. No es el hombre el que se pregunta por el sentido de la vida sino que más bien sucede al revés; el interrogado es el propio hombre. Si en el psicoanálisis viene a hacerse consciente lo impulsivo, en el análisis existencial es hecho consciente lo espiritual, ya que lo verdaderamente humano se vislumbra en la dimensión de lo espiritual. La metafísica de la persona nos ayuda en un doble paso: de la facticidad psicofísica a la existencialidad espiritual del hombre y de la existencia a la trascendencia.

Se trata de movilizar la existencia espiritual en el sentido de un estado de responsabilidad libre que nos ponga la existencia ante los ojos, contraponiéndola así a la facticidad psicofísica. No podemos hablar del hombre como de una totalidad corpóreo-anímica: cuerpo y alma pueden formar una unidad psicofísica, pero jamás dicha unidad puede representar la totalidad humana. En cada uno de nosotros existe una doble unidad: la de naturaleza y la de persona. Por la unidad de naturaleza, el alma se une al cuerpo para perfeccionarlo formalmente y constituyendo con él una naturaleza individual y concreta; y por la unidad de persona, dicha unión se constituye en un subsistens distinctum en cuerpo y alma.

Algo muy parecido expresa Frankl cuando afirma la existencia de un eje que atraviesa el consciente, el preconsciente y el inconsciente de la persona, una especie de persona profunda, la persona espiritual-existencial del yo propio y auténtico en sí mismo. Frankl extiende el análisis existencial a la totalidad del hombre que no es sólo psicofísico sino espiritual-personal. Y es que el hombre es esencialmente el ser que trasciende las necesidades; existe en una relación libre respecto a ellas. Un hombre es sólo persona en la medida en que - como ser espiritual- está por encima de su ser corporal y psíquico. En cualquier momento, el hombre toma posición frente al mundo, externo o interno. La existencia está en la facticidad pero no se agota en ella. El que ex-siste está por encima de su propia facticidad. Una vez más la filosofía cristiana supo inscribir el ser y el actuar de la persona en el interior de la ontología de los espíritus creados dando a la antropología una especial fecundidad existencial.

Univ. Ramón Llull (Barcelona)

Joan Martínez Porcell

Facultad de Filosofía

Grupo de investigación «Filosofía i Cultura»

joanmartinezporcell@gmail.com

[artículo aprobado para publicación en noviembre de 2013] 
